\title{
Drawing, Visualization and Augmented Reality of the I79| Celebration in Naples
}

\author{
Ornella Zerlenga \\ Vincenzo Cirillo \\ Massimiliano Masullo \\ Aniello Pascale \\ Luigi Maffei
}

\section{Abstract}

This paper investigates the ephemeral architecture of the eighteenth century in Naples through the literary and iconographic sources found in the volume Idee per le pubbliche feste nel ritorno in Napoli de'nostri Augusti Sovrani dalla Germania [...] by Gaetano Barba (1971). The goal is an unprecedented representation, modeling and fruition project, accompanied by a graphic visualization of the places to better understand the architectural and urban space in the absence of allusive images of three-dimensionality. Subsequently, the visual construction of the contexts on an urban and architectural scale made it possible to disseminate the compositional elements of the celebrations and the internal perceptions to a non-specialist public. Finally, an Augmented-Reality application prototype.

Keywords

ephemeral architecture, celebrations, representation, 3D modeling, augmented reality.

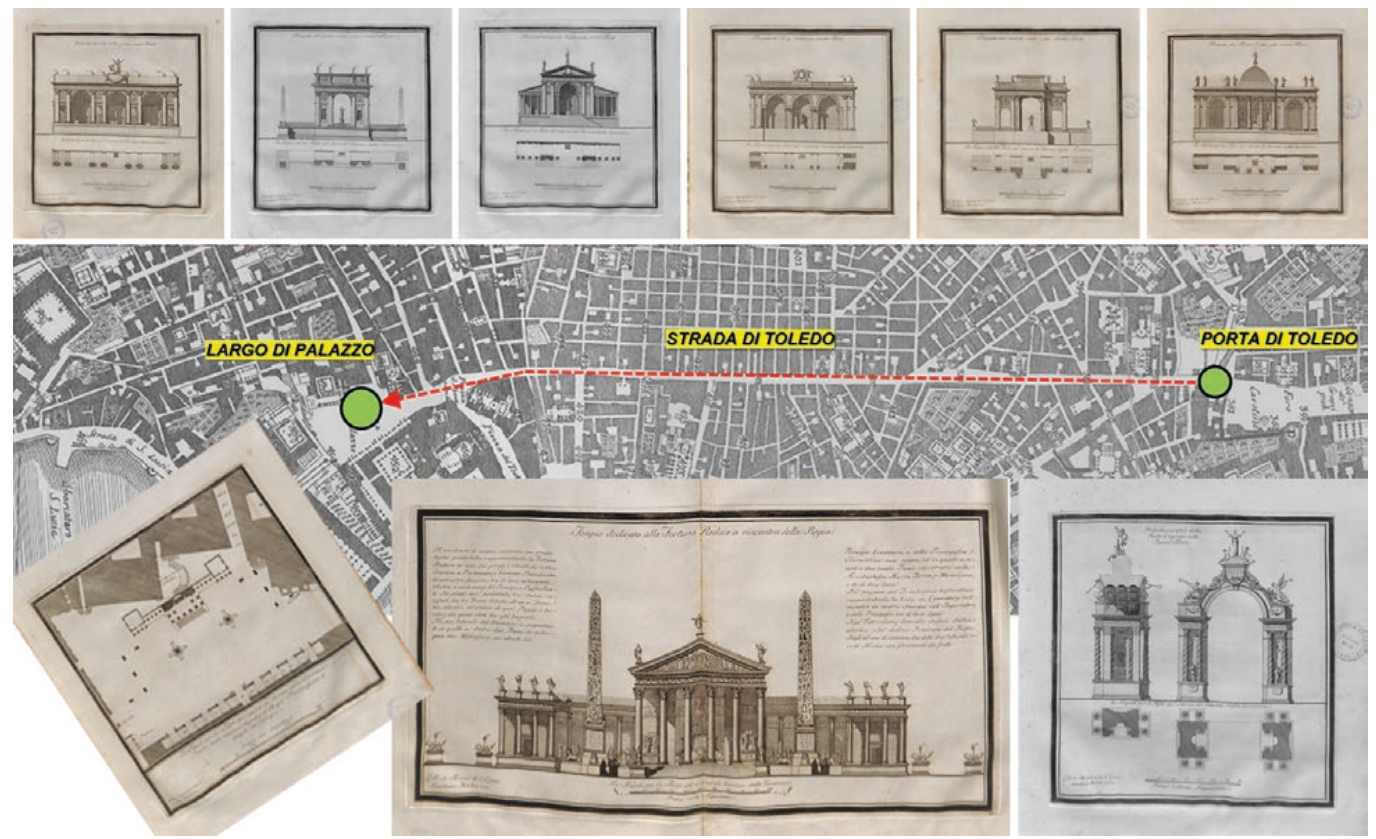


Through the synergy between the disciplines of Drawing and Technical Physics, this contribution analyzes the methods of graphic representation and the digital modeling of the eighteenth-century celebration designed (and not realized) in I79 I by the architect Gaetano Barba (1730I806) in Naples and described in the volume entitled: Idee per le pubbliche Feste nel ritorno in Napoli de' Nostri Augusti Sovrani dalla Germania dell'architetto Gaetano Barba, Accademico di merito di S. Luca, edito a Napoli nel I 79 I da Gaetano Raimondi.

The results achieved with the graphic analysis and the build of new images are intended to represent, thanks to the aid of digital representation methods, both a cultural contextualization of the methods of representation used, and the return of a three-dimensional model to be understood as a phase of a subsequent study aimed at verifying the new technologies of virtual representation at the service of cultural tourism. The goal is to make the design 'augmented' so that the visitor can relive the context of the I 8th century Neapolitan celebrations. Therefore, it is proposed as an application case, the virtual reconstruction of the Porta di ingresso sulla strada di Toledo and its implementation in an Augmented Reality application. The application conceived for this purpose was created with the support of SENS i-Lab, a human-centered, multi-physical and multi-purpose university laboratory for the creation, development, prototyping and interaction of man with products and physical and virtual systems of the Department of Architecture, Industrial Design of the University of Campania Luigi Vanvitelli [I].

\section{The Drawing of the Ephemeral: the Regulating Principle of the 197I Celebration in Naples by Gaetano Barba}

The ephemeral concept has been (and continues to be) for the city of Naples a constant cultural expression, which is poured out not only in the everyday life of the people but also, and above all, in its architecture. The design of ephemeral architectures (such as fairs, cuccagne, pyrotechnic machines) saw widespread use in Naples during the eighteenth century with the creation of installations with a considerable design value [Cirillo 20 I7, pp. I0 I - I I 8].

The theme of the 'urban' celebrationl reached one of its most significant moments in the eighteenth century with the staging of ephemeral settings that manifested the greatest affirmation of the culture and Art of that time. Their realization relied on a great variety of technical (architects and engineers), figurative and entertainment skills (musicians, painters, set designers).This synergy highlighted the taste for spectacularity, grandeur, sumptuousness and the decoration of the apparatuses to arouse the effect of wonder [Mancini 1997].

Within this context, in August 1790 in Naples, in the place called Largo di Palazzo (the open space in front of the Royal Palace) and along Via Toledo, a cycle of festivities was celebrated in honor of the return of the kings of Naples, Ferdinando and Maria Carolina, who were in Vienna for the wedding of their daughters Maria Teresa and Maria Luisa. To celebrate this return, a competition was held between the best architects of that time. The celebrations' principles were banned and published in the volume entitled Nel felicissimo ritorno degli Augusti Sovrani Ferdinando IV e Maria Carolina d'Austria. Feste Pubbliche della Fedelissima Città di Napoli (I 79I) at Giuseppe Maria Porcelli Librajo, e Stampatore della Reale Accademia Militare. The aforementioned volume reports as winner the set designer of the San Carlo theater Domenico Chelli, but there is no iconographic documentation about his project. However, Chelli, also with small formal changes, was inspired by the project outlined by the architect Gaetano Barba published in the same year in the volume Idee per le pubbliche Feste nel ritorno in Napoli [...] [Mancini 1980, p. 33 I].

The volume Idee per le pubbliche Feste nel ritorno in Napoli [... ] by Gaetano Barba accompanies the reader to understanding the events not only through the reading of the short text but above all through the attached images. The images contained within the volume consists in ten engravings of the architectural elements, which set up the celebration. These representations appear ordered according to a spatial sequence which, starting from the Porta di ingresso sulla strada di Toledo and through the Sedili located along Via Toledo, leads to the rear scene of the Tempio dedicato alla Fortuna reduce, set up in Largo di Palazzo (opening figure). All the engravings show the architectural organisms represented in plan and/or elevation with full adherence to the neoclassical style [lacazzi 1995]. The architect offers a general description of all the elements of the celebration and outlines both their appearance and their functions and destinations. 
The installation of the entrance door was placed where the Ancient Royal Gate, also known as the Spirito Santo (current south side of Piazza Dante). Later, the celebrations would continue along Via Toledo, which was to be adorned and decorated with six Sedili (seats), called Ornati Architettonici di rilievo, which would have had the task of embellishing and making the façades of the street more pleasant.

The six seats suggest that they would have been arranged with the long side parallel to the road axis. In this sense, it is plausible to think that these structures would have leaned on the elevations of the buildings on Via Toledo, both for the lack of a second elevation in the back and for the analogy with other festivals such as, for example, that of Santa Rosalia in Palermo where ephemeral structures were placed on the facades of existing buildings [Isgrò 20 I 9; Di Fede 2005-2006, pp. 49-75]. In Largo di Palazzo, a majestic Temple dedicated to Fortuna Reduce would have concluded the festive itinerary. The temple with colonnades, a large central staircase, two obelisks, statues and two arms of pedestals surmounted by statues of sirens, would have stretched towards the statue of the Giant and the Church of the Santo Spirito (demolished), thus redesigning the planimetric layout of the square with a regular shape. The drawings by Gaetano Barba allowed a correct and meticulous analysis and representation of all the elements designed, thus succeeding in grasping the dimensional and spatial character of each structure. In this sense, starting from the literal description, from the project drawings and from a conversion into meters of the dimensions indicated in 'Neapolitan palms', through graphic analysis, modeling and subsequent visualization (fig. I, above) an unpublished image is returned. of the event according to the criteria and ideas of Gaetano Barba respecting the urban context of the Neapolitan eighteenth century (fig. I, below). Given this, the digital reconstruction of the entrance door and the virtual location in the current Piazza Dante through the AR application constitute the case study for visualizing both the party imagined by the designer and the actualization effect.
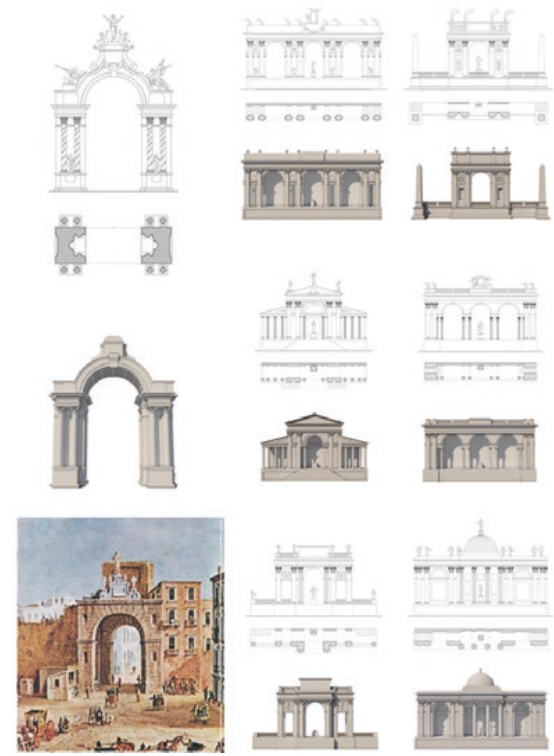
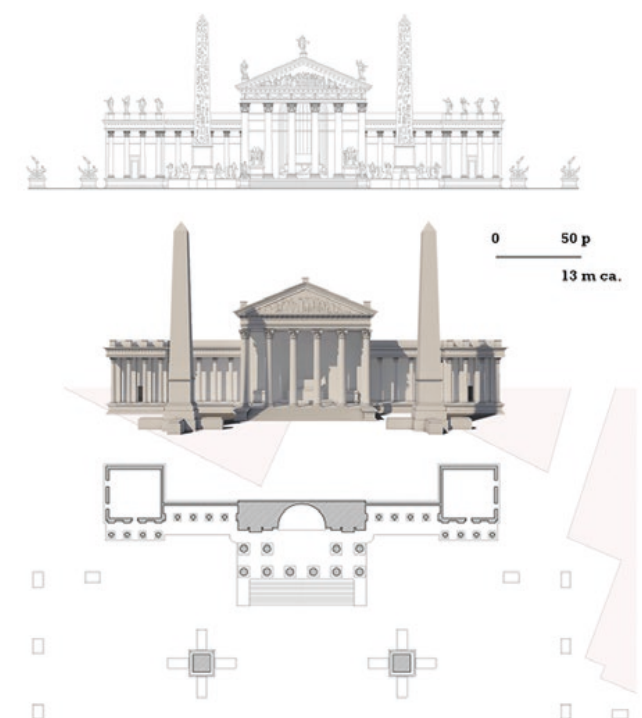

Fig. I. Above, Entrance Door, Seats and Temple of Fortuna Reduce: planaltrimetric drawings and 3D modeling; below, visualization of the Temple of Fortun Reduce in Largo di Palazzo (drawing and Palazzo (drawngs and graphic elaborations by Vincenzo Cirillo).

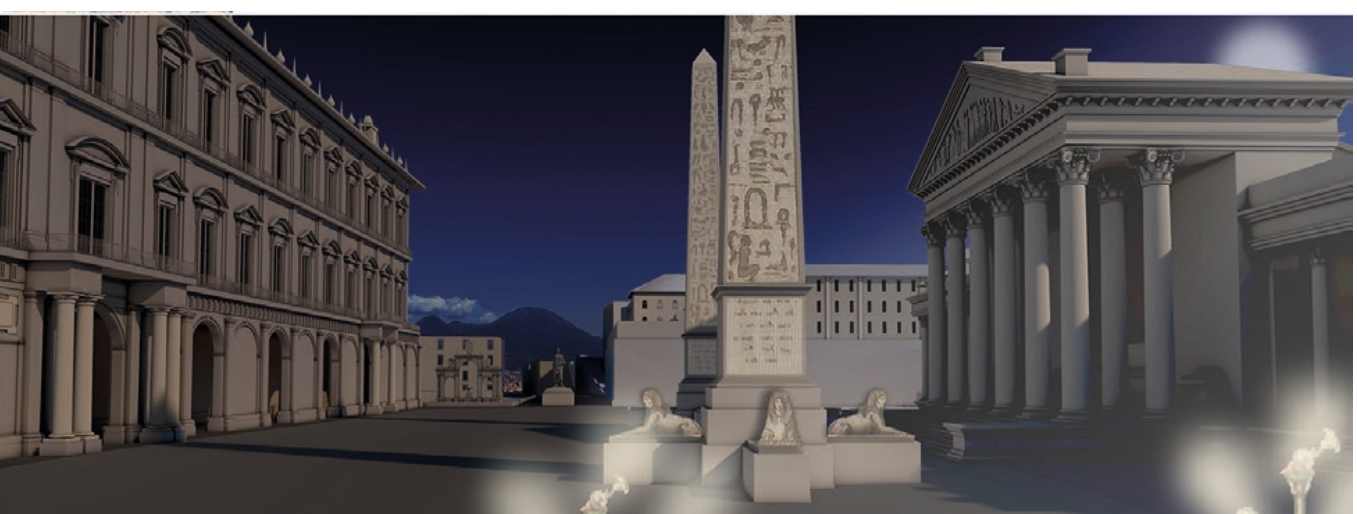




\section{The Prototype of the Application in AR}

The development of digital content that can be used through mass-market devices (e.g. mobile phones, tablets) and head-mounted displays in the last decade has found a fertile field of application in the world of Cultural Heritage [Voinea 20।8]. More and more varied and interactive digital contents, accompanying the offer to tourists, are having increasingly interesting implications: (I) the possibility of visiting sites that no longer exist or are inaccessible represents an opportunity for museums to expand the offer of contents and cultural sites, with the ability to attract and intrigue even a younger user target; (2) the digital contents are conveyed to the end-user directly, providing them with a more or less immersing experience according to the types of devices in use. (3) The digital contents are made available to the user through their smartphone, with the possibility to contextualize it in its original place. Taking advantage of the opportunities deriving from Digital Cultural Heritage applications, an App prototype has been created. Through the Augmented Reality (AR), the App allows users to walk through the streets of a city, its monuments, artefacts, lost buildings or, in any case, not accessible. The first application concerned the artefact of the entrance door sited in Via Toledo in AR. The workflow sees a first phase dedicated to creating the contents necessary for developing the App:Three-dimensional model, Texture, Sounds. The three-dimensional model was made starting from the drawings recovered in the bibliography, as described above. In this phase, more attention was focused on defining the details of the 3D model: frames, moldings, capitals, rather than on the materials. It was important to create a reasonably light model in terms of 'vertex counting' which, however, did not compromise the elements' definition. The complete model in all parts was then exported to the 3DsMax software for polygon optimization and asset preparation. In particular, the elements that make up the product have been appropriately divided, and IDs have been assigned for the diversification of materials. The textures were downloaded from Megascans libraries. As for creating sounds, a sound effects composition operation was carried out, starting from professional libraries' sounds. Anthropogenic sounds such as pedestrian footsteps, people's voices, and music have been downloaded to recreate the party's typical sound setting. The sounds have been converted all mono and imported into the development environment. Here they have been inserted as points sound-source so that you can make a spatialization of the sound. The App was created within the 'Unreal Engine 4' development environment. The ARCore framework, necessary for the recognition functions of surface planes in AR mode, was implemented here. A basic interface has been inserted that allows the user to enable the camera and frame the horizontal plane where the 3D model will be displayed.The actor was then created to be placed on the surface, with the artefact's 3D model inside. Once the floors are recognized, a tap on the screen allows you to position the object; subsequent finger gestures will enable you to move and rotate it (fig. 2). A first test was carried out directly on site. In piazza Dante, near the beginning of

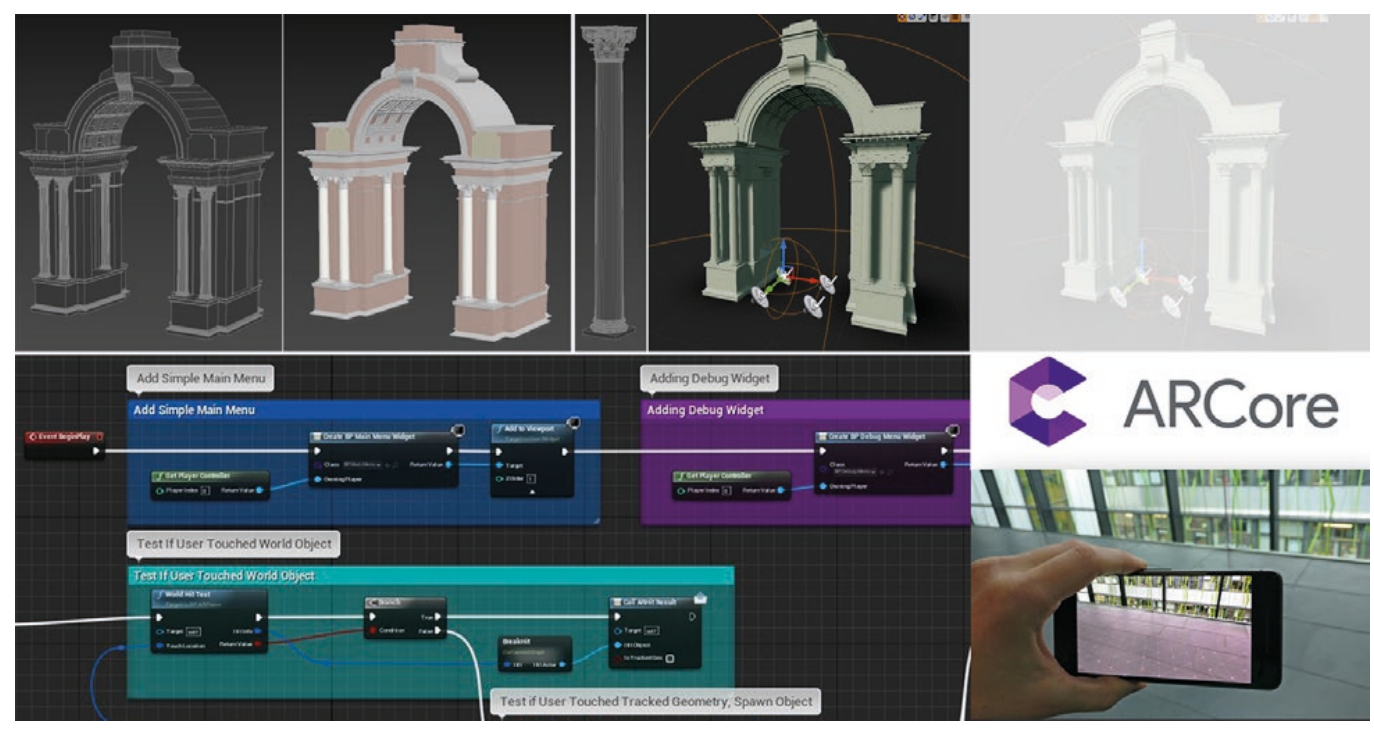


Fig. 3. From left, Micco Spadaro (XVII secolo) Punizione dei ladri al tempo di Masaniello; Insertion test of the artefact in the original site.
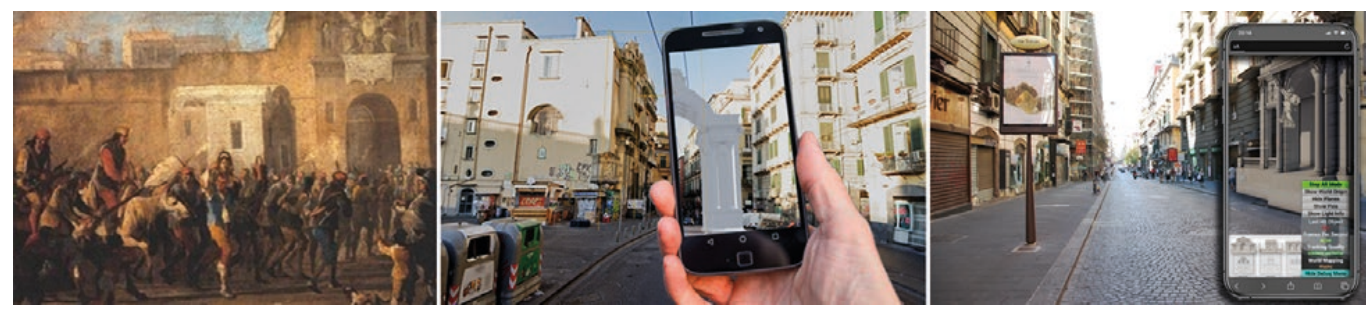

via Toledo, the artefact was positioned. After recognizing the support surface's height, the operator could place the artefact easily and explore it from the most congenial point of view. During the experience, the sounds, located almost under the arch, helped to realize what Porta Toledo's installation must have been, in the place where it was designed (fig. 3).

\section{Conclusions}

On the basis of the sources collected and through the discipline of drawing, this paper analyzes the project of the 'Pubbliche feste [...]' by Gaetano Barba ( 1791 ). Accompanied by unpublished graphic elaborations, the paper describes the architectural elements that make up the celebration through an 'augmented' design. In this sense, the virtual reconstruction of the entrance door on Via Toledo and its implementation in an Augmented Reality application was proposed as an application case. The choice to contextualize AR to the current urban situation instead of set it in the late eighteenth century results from the fact that the research group is analyzing the design and reconstruction of other eighteenth-century Neapolitan celebrations. Therefore, the reconstruction of the eighteenth-century city will be formulated as future works where will be evaluated the different urban places, sometimes, modified in relation to the ephemeral architectures construction.

\section{Notes}

[I] The research presented is the result of the joint work of the five authors. The paragraphs Introduction and Conclusions is written by Ornella Zerlenga and Luigi Maffei; the paragraph The drawing of the ephemeral: the regulating principle of the 1971 celebration in Naples by Gaetano Barba by Vincenzo Cirillo and the paragraph The prototype of the application in AR by Massimiliano Masullo and Aniello Pascale.

\section{References}

Cirillo Vincenzo (20 |7). Riflessioni su disegno e visualizzazione della Fiera del |738. In Eikonocity, 2, || (I), pp. |0 | - | 8.

Di Fede Maria Sofia (2005-2006). La festa barocca a Palermo: città, architetture, istituzioni | Baroque Festival in Palermo: City, Architectures and Institutions. In Espacio, Tiempo y Forma, Serie VII, H.a del Arte, I 8-19, pp. 49-75.

Idee per le pubbliche Feste nel ritorno in Napoli de' Nostri Augusti Sovrani dalla Germania dell'architetto Gaetano Barba,Accademico di merito di S. Luca (197I). Napoli: Gaetano Raimondi.

Isgrò Giovanni (2019). L'idea del teatro festivo urbano e lo status anomalo dello spettacolo in Sicilia. http://www.istitutoeuroarabo. it/DM/lidea-del-teatro-festivo-urbano-e-lo-status-anomalo-dello-spettacolo-in-sicilia/ (8 January 2021 ).

Jacazzi Danila (1995). Gaetano Barba architetto «neapolitano» 1730-1806. Napoli: Edizioni Scientifiche Italiane.

Mancini Franco (1997). Feste e apparati civili e religiosi in Napoli dal viceregno alla capitale. Napoli: Edizioni Scientifiche Italiane.

Mancini Franco (1980). II 'trucco' urbano: apparati e scenografie tra finzione e realtà. In Civiltà del '700 a Napoli 1734 - I 799. Napoli: Edizioni Scientifiche Italiane, pp. 331 - 333.

Nel felicissimo ritorno degli Augusti Sovrani Ferdinando IV e Maria Carolina d'Austria. Feste Pubbliche della Fedelissima Città di Napoli Nel felicissimo ritorno degli Augusti Sovrani
(|79I). Napoli: Giuseppe Maria Porcelli.

Voinea Gheorghe-Daniel, Girbacia Florin, Postelnicu Cristian Cezar, Marto Anabela (20 I8). Exploring Cultural Heritage Using Augmented Reality Through Google's Project Tango and ARCore. First International Conference, VRTCH, pp. $93-106$.

\section{Authors}

Ornella Zerlenga, Dept. of Architecture and Industrial Design, University of Campania LuigiVanvitelli, ornella.zerlenga@unicampania.it Vincenzo Cirillo, Dept. of Architecture and Industrial Design, University of Campania Luigi Vanvitelli, vincenzo.cirillo@unicampania.it Massimiliano Masullo, Dept. of Arch. and Industrial Design, University of Campania LuigiVanvitelli, massimiliano.masullo@unicampania.it Aniello Pascale, Dept. of Architecture and Industrial Design, University of Campania Luigi Vanvitelli, aniello.pascale@unicampania.it Luigi Maffei, Dept. of Architecture and Industrial Design, University of Campania Luigi Vanvitelli, luigi.maffei@unicampania.it 
